\title{
Optimization of Car Suspension Parameters Using Genetic Algorithms
}

\author{
Elhem Barkallah $^{\mathrm{a}}$, Nesrine Majdoub ${ }^{\mathrm{b}}$, Anis Sakly ${ }^{\mathrm{c}}$, Kamel Ben Othman ${ }^{\mathrm{d}}$ \\ ${ }^{a}$ University of Gabes, National Engineering School of Gabes, Gabes-6029, Tunisia \\ ${ }^{\mathrm{b}}$ University of Monastir, National Engineering School of Monastir, Monastir-5000, Tunisia, \\ ${ }^{c}$ University of Monastir, National Engineering School of Monastir, Monastir-5000, Tunisia \\ ${ }^{\mathrm{d}}$ University of Monastir, National Engineering School of Monastir, Monastir-5000, Tunisia
}

Correspondence Author: Elhem Barkallah, Doctoral School "Sciences, Engineering and Society," National Engineering School of Gabes, University of Gabes. E-mail : elhem.barkallah@gmail.com

\section{Received date: 20 May 2019, Accepted date: 15 July 2019, Online date: 28 July 2019}

Copyright: (C) 2019 Elhem Barkallah et al., This is an open-access article distributed under the terms of the Creative Commons Attribution License, which permits unrestricted use, distribution, and reproduction in any medium, provided the original author and source are credited.

\begin{abstract}
The design of suspension system has been one of the challenging tasks because it is in a relationship with the passenger comfort. The main function of the car suspension is to reduce the vibrations of the vehicle body transmitted from the road excitations. The aim of this work is to model the « Passive car suspension » using Bond graph and to improve the system performance by optimizing its parameters using the genetic algorithms. The cost function of this algorithm depends of the commandability and observability gramians.
\end{abstract}

Keywords: Car Suspension, Modeling, Bond Graph, Optimization, Genetic Algorithms, and Gramian

\section{INTRODUCTION}

Mechatronic systems, in particular, and active dynamics, in general, require a design approach that must support their multidisciplinarity and supports the integration of constraints imposed by each discipline (H. Amara 2011).

Modeling these systems makes it possible to study real phenomena and predict results at a given level of approximation. Mathematical models can be complex and difficult to interpret. For this reason, in the last decades, several graphic tools have been developed, among which we can find block diagrams, fluence graphs, Bond Graphs, Graph Causal Information and Macroscopic Energy Representation (R. Sanchez 2010).

Once the system is modeled, comes a step of dimensioning of the different systems' elements. It is a delicate phase because it will define the system's performance. For that, designers search for optimal dimensioning. The optimization of mechatronic operations makes part of the design research. Design methodology uses optimization in routine design when we modify some values of structural components and validate by simulations.

In this work, we chose to study the suspension system since it is the responsibility of the passenger comfort, the most critical parameter in the design and manufacturing of automobiles. The suspension system carries the weight of vehicle structure, driver and passenger, and it absorbs the vibrations passing to the vehicle body from the road. These vibrations are mainly due to irregularities in the road surface, aerodynamic forces and non-uniform wheel assembly and out of these surface irregularities are predominant. For that, the suspension dimensioning is very delicate (A. Mitra 2015).

Section 2 is devoted to the presentation of modeling the suspension system via the bond graph tool. In section 3, we present the optimization approach based on the Genetic Algorithms (GA) and its application on the suspension parameters. Section 4 consists of making a dynamic simulation to validate our optimization algorithm and we compared the system's performance using the optimized parameters and the parameters of the article (A. Florin). Section 5 concludes this paper.

\section{MODELING}

The modeling phase must be supported by tools that must manage, on the one hand, the multidisciplinarity of dynamic, active systems and the functional, structural and behavioral aspects on the other hand. That is why we choose the bond graph tool, which is an intermediary between the physical system and its associated mathematical models (Dauphin-Tanguy, 2000). 


\section{Bond Graph}

A bond graph (BG) is an engineering tool based on the description of physical systems by analyzing the exchange of energy within. This exchange determines the dynamic behavior of the systems (R. Zrafi 2018).

The principle of BG is to represent the energy exchanges between two elements by a half arrow called a power bond, describing the direction of the transfer. This transfer is characterized by two variables: a force and a flux whose product is equal to the power exchanged $\mathrm{P}(\mathrm{t})$.

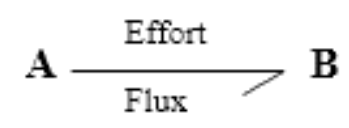

\section{System}

The example studied is the passive suspension of a car, from the article in (A. Florin).

Figure 1: Car suspension

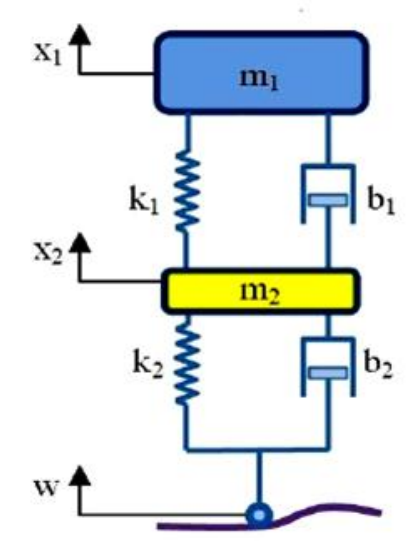

$\mathrm{m} 1$ : mass of the vehicle $(\mathrm{Kg})$

$\mathrm{m} 2$ : mass of the wheel $(\mathrm{Kg})$

$\mathrm{k} 1$ : spring stiffness

$\mathrm{k} 2$ : tire stiffness

b1: shock absorber, fluid friction

b2: shock absorber

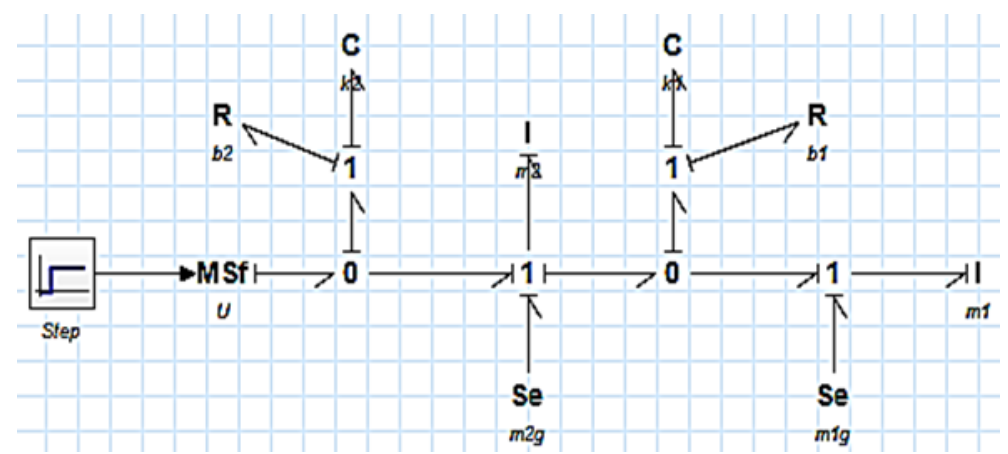

Figure 2: Bond graph model of the car suspension

\section{State Model}

From the bond graph model, we can synthesise the state model.

The transition from a bond-graph representation of a system to a state formulation is quite natural. The components of the vector will be the energy variables associated with elements I and C (J.M Retif 2008).

The state vector is, therefore: $\quad X=\left[\begin{array}{l}p i \\ q c\end{array}\right] \quad d X=\left[\begin{array}{l}e i \\ f c\end{array}\right]$

The state matrix of our example is: 
$A=\left[\begin{array}{cccc}\frac{-b 1}{m 1} & \frac{b 1}{m 1} & \frac{-k 1}{m 1} & \frac{k 1}{m 1} \\ \frac{b 1}{m 2} & \frac{-(b 1+b 2)}{m 2} & \frac{k 1}{m 2} & \frac{-(k 1+k 2)}{m 2} \\ 1 & 0 & 0 & 0 \\ 0 & 1 & 0 & 0\end{array}\right] \quad B=\left[\begin{array}{cc}0 & 0 \\ \frac{b 2}{m 2} & \frac{k 2}{m 2} \\ 0 & 0 \\ 0 & 0\end{array}\right] \quad C=\left[\begin{array}{llll}0 & \frac{1}{m 1} & 0 & 0\end{array}\right] \quad D=\left[\begin{array}{lll}0 & 0 & 0\end{array}\right]$

\section{OPTIMIZATION}

\section{Genetic Algorithms}

The Genetic Algorithm is a meta-heuristic commonly used to solve optimization problems. The first GAs, introduced in 1975 by John Holland, only transpose what nature does to artificial systems. They simulate the evolutionary Darwinian and genetic processes that apply to chromosomes. They transform a set of mathematical objects; a population of individuals often represented by strings of characters to mimic the DNA strings each with an adaptation value, into a new population (N. Durand 2004).

A GA is used to search the global extremum of a function defined on a data space.

To apply the GA, the following steps must be followed:

- Generation of the initial population: This mechanism must be capable of producing a non-homogeneous population of individuals (chromosomes) that will serve as a basis for future generations.

- Coding: A population is a set of the individual. Each is encoded as a vector of length $\mathrm{L}$ (the chromosome $\mathrm{g}$ ), in which each element represents a gene $\mathrm{g}_{\mathrm{k}}$ : $\mathrm{g}=\left(\mathrm{g}_{1}, \mathrm{~g}_{2}, \ldots, \mathrm{g}_{\mathrm{L}}\right)(\mathrm{N}$. Majdoub 2011).

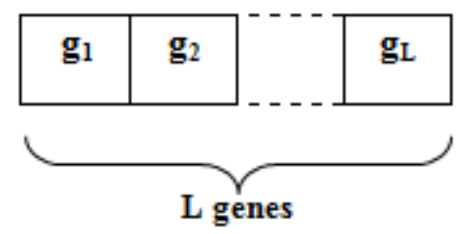

Figure 1: Chromosome structure

- Fixing the fitness evaluation function: This is the cost function to optimize. It is called fitness or evaluation function of the individual. It represents the objective function of an optimization problem.

- Selection: Selection is used to determine which individuals will be useful for the crossover operation and the generation of the new population $(\mathrm{Gen}+\mathrm{i})$ to be evaluated.

- Crossover: The purpose of the crossing operation is to enrich and diversify the population by combining individuals by manipulating the structure of chromosomes. This operation is applied between two parents of the population to generate one or two children.

- Mutation: The mutation allows a diversified, random and efficient exploration of the research space. Without mutation, the solution can converge to a local solution.

- Insert: This is done after the mutation to generate a new population.

- Define a stop Criterion: The stopping test plays a very important role in judging program quality from speed and accuracy of results. The criteria for stopping are of two types: Stop after a fixed number of generations or error reached.

\section{Implementation}

To optimize the car suspension system, we consider in this paper that each gene represents a parameter. Therefore, the length of each chromosome (individual) is six, equal to the number of the system's parameters: $\mathrm{m} 1, \mathrm{~m} 2, \mathrm{k} 1, \mathrm{k} 2, \mathrm{~b} 1$ and $\mathrm{b} 2$.

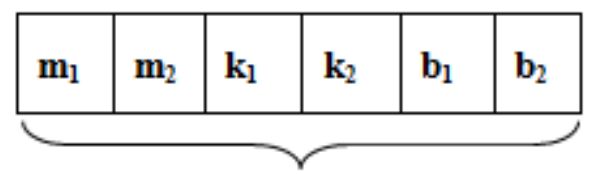

Six genes

Figure 2: Elements of our chromosome

The procedure mentioned in 3.1 was followed.

Step1:

- define the parameters of the algorithm:

- Population size: $\mathrm{n}=40$

- Maximum generation: maxgen $=60$ generations 
- Probability of crossover: crossp $=0.9$

- Probability of mutation: mutate $=0.2$

- Fix the interval of existence of the parameters used by the genetic algorithms.

Table 1: Interval of the parameters

\begin{tabular}{|c|c|c|c|c|c|c|}
\hline Interval & $\mathbf{m}_{\mathbf{1}}$ & $\mathbf{m}_{\mathbf{2}}$ & $\mathbf{k}_{\mathbf{1}}$ & $\mathbf{k}_{\mathbf{2}}$ & $\mathbf{b}_{\mathbf{1}}$ & $\mathbf{b}_{\mathbf{2}}$ \\
\hline $\mathbf{X}_{\min }$ & 280 & 30 & 3000 & 130000 & 250 & 250 \\
\hline $\mathbf{X}_{\max }$ & 500 & 50 & 5000 & 170000 & 1400 & 1400 \\
\hline
\end{tabular}

\section{Step2:}

-Define fitness function. We propose the trace of the controllability gramian and observability gramians (B. Marx 2004) (M. Nasri).

Indeed, in the case of mechatronic systems, the minimal energy to be supplied to the system to reach a given state is inversely proportional to gramian of controllability and the energy of output generated by a given initial state is proportional to gramian of observability (B. Marx 2002)

- Controllability gramian: $W_{c}(t)=\int_{0}^{t} e^{A t} \cdot B \cdot B^{t} \cdot e^{A^{t} t} d t$

- Observability gramian : $W_{o}(t)=\int_{0}^{t} e^{A^{t} t} \cdot C^{t} \cdot C \cdot e^{A t} d t$

These gramians are also determined by solving the Lyapunov equations (H. Amara 2011):

$W_{c}: A X+X A^{T}+B^{T} B=0$

$W_{o}: A^{T} X+A X+C C^{T}=0$

\section{Step3:}

- Generate randomly the initial population,

- Coding used in our approach is real.

- Initialize the iterations index it,

Then the initial population is a random (but limited in the interval of existence of the parameters) matrix of six rows and forty lines.

\section{Step4:}

- By solving an optimal control problem, evaluate and assign fitness values to individuals in the population,

- identify the individual corresponding to the maximum cost,

- Produce children of parents selected by crossing,

- Mutate children (new population),

- By solving an optimal control problem, evaluate and assign fitness values to the child,

- Identify the child corresponding to the maximum cost,

- Insert the individual, corresponding to the initial maximum cost, to the new population.

\section{Step 5:}

- Increment it,

- Compare the iteration index and max gen,

- If it <, maxgen then return to step4, else go to step6

\section{Step 6:}

- Return the best individual for the optimum cost; the chromosome of the maximum fitness function for the suspension system.

\section{Optimization Results}

The optimal solution, obtained by GA during the maximization of the sum of the trace of observability gramian and the trace of controllability gramian, is presented by the following table in addition to the parameters used in the article.

Table 2: Optimized parameters

\begin{tabular}{|c|c|c|c|c|c|c|}
\hline & $\mathbf{m}_{\mathbf{1}}$ & $\mathbf{m}_{\mathbf{2}}$ & $\mathbf{k}_{\mathbf{1}}$ & $\mathbf{k}_{\mathbf{2}}$ & $\mathbf{b}_{\mathbf{1}}$ & $\mathbf{b}_{\mathbf{2}}$ \\
\hline $\mathbf{X}_{\text {optimal }}$ & 283.8 & 30 & 4325 & 169950 & 252.2 & 1397 \\
\hline $\mathbf{X}_{\text {article }}$ & 466.5 & 49.8 & 5700 & 135000 & 290 & 1400 \\
\hline
\end{tabular}

\section{SIMULATION AND RESULTS}

From the equations related to the bond graph junctions, it is easy to define the simulation block diagram.

For the input signal, we tried some signals that look like difficult roads to visualize the car body displacement.

The results are shown by the following curves: 
Citation: Elhem Barkallah, et al., Optimization of Car Suspension Parameters Using Genetic Algorithms. Australian Journal of Basic and Applied Sciences, 13(7): 6-11. DOI: 10.22587/ajbas.2019.13.7.2

- The red curve is the input signal; $\mathrm{U}$.

- The orange curve is the car body displacement using the article parameters; Y1.

- The green curve is the car body displacement using the optimized parameters; Y2.

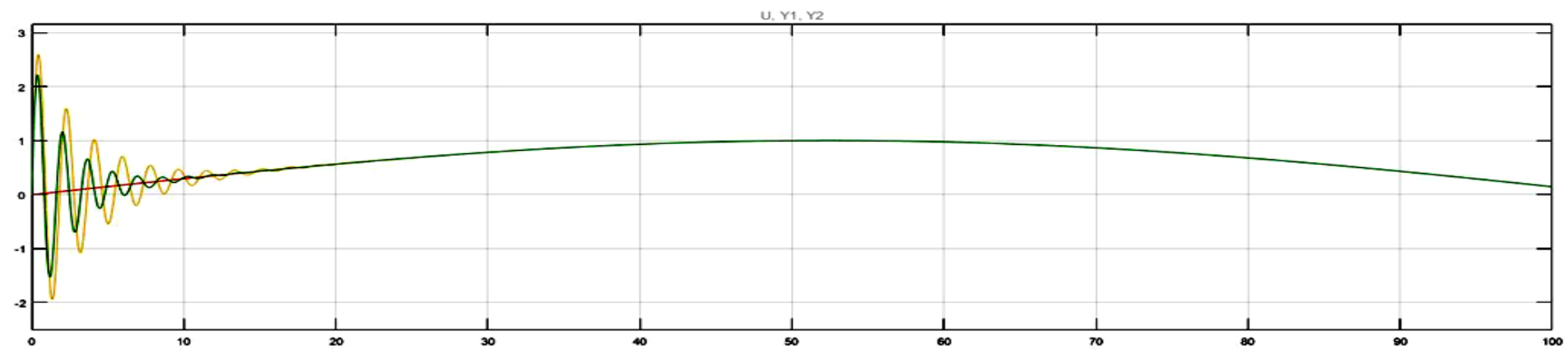

Figure 3: Sinusoidal input

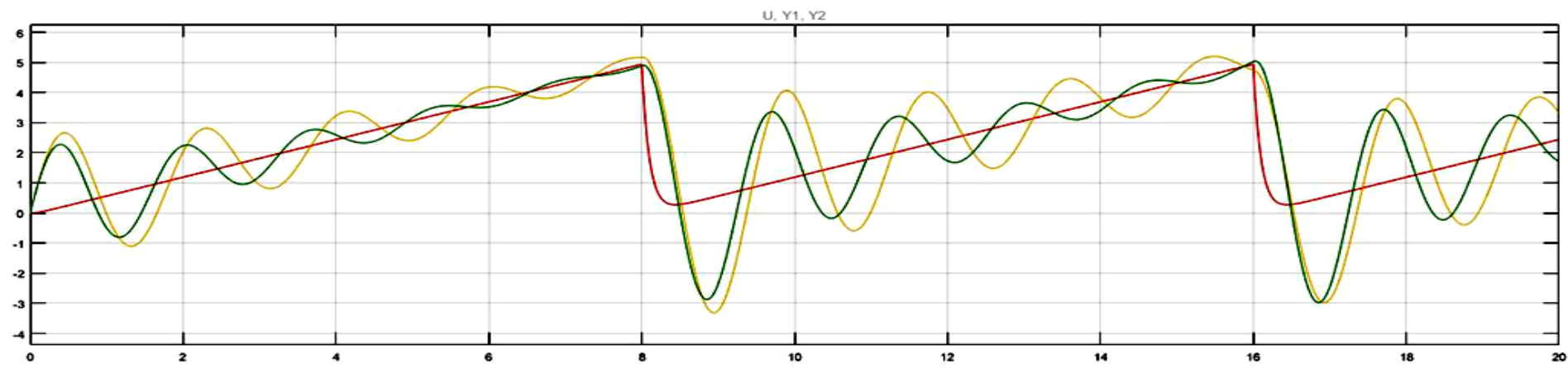

Figure 4: Triangular input

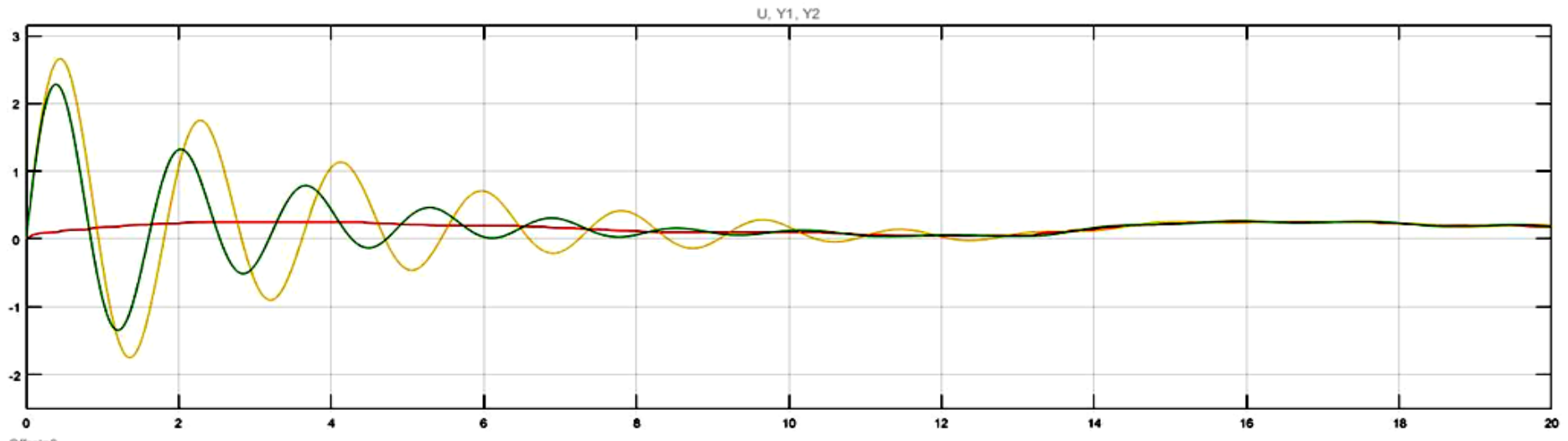

Figure 5: Random input

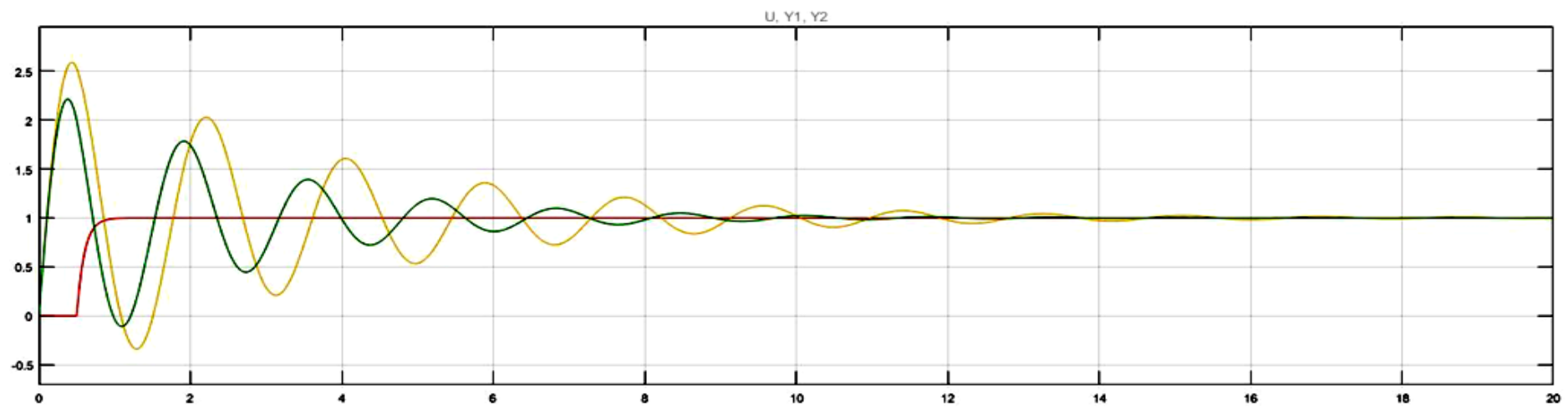

Figure 6: Step input 
Comparing the results, the difference is so clear:

- $\quad$ Y2 reach the steady-state 5 s before $\mathrm{Y} 1$

- Oscillation amplitude of $\mathrm{Y} 2$ is 0.5 less than that of $\mathrm{Y} 1$

The main function of any suspension system is to absorb the road excitations transmitted to the vehicle body.

$\rightarrow$ We can deduct that using the optimized parameters; we improved the system performances.

\section{CONCLUSION}

In this paper, we proposed a dimensioning procedure of mechatronic systems using the bond graph for the modeling and the genetic algorithms for the optimization. This procedure is validated on the example «Passive suspension modeling using MATLAB, quarter car model, input signal step type» (A. Florin). In this frame, we demonstrated that the model is more performing using the optimized parameters than those of the article.

\section{REFERENCES}

A. Florin, M. Ioan-Cozmin, P. Liliana «Pasive Suspension Modeling Using Matlab, Quarter Car Model, Input Signal Step Type»

A. Mitraa, G. Desaib, S. Patwardhanc, P. Shirked, W. Kurnee, N. Banerjeef (2015) "Optimization Of Passive Vehicle Suspension System By Genetic Algorithm" 12th International Conference on Vibration Problems, ICOVP

B. Marx, D. Koenig, D. Georges, (2002) "Optimals Ensor/Actuator Location For Descriptor Systems Using Lyapunov-Like Equ Ation", Conference on Decision and Control Las Vegas, Nevada USA

B. Marx, D. Koenig, D. Georges (2004) "Optimal Sensor and Actuator Location for Descriptor Systems using Generalized Gramians and Balanced Realizations", Proceedings of the American Control Conference

D. Ondo, L. Lefèvre, B. Chopard «Commandabilité d'un modèle de Boltzmann sur réseau d'écoulements en eau peu profondes »

Dauphin Tanguy (2000), "Les Bond Graphs" (série système automatisés), Lavoisier edition.

H. Amara (2011) «Optimisation multicritère des systèmes dynamique actifs », Master's thesis, National Engineering School of Monastir

J.M RETIF (2008) “Automatique Modelistion” National Institute of Applied Sciences of Lyon

M. Nasri and M. EL Hitmy « Algorithme Génétique et Critère de la Trace pour l'Optimisation du Vecteur Attribut : Application à la Classification Supervisée des Images de Textures », Ecole Supérieure de Technologie, Maroc

N. Durand, (2004)« Algorithmes Génétiques et autres méthodes d'optimisation appliqués à la gestion de trafic aérien », Ability to conduct researches, The Polytechnic National Institute Of Toulouse

N. Majdoub (2011) "Modélisation et Synthèse de Lois de Commande Performantes de Systèmes Dynamiques Hybrides », Doctoral thesis, National Engineering School of Tunis

R. Sanchez (2010) «Application Des Bond Graphs À La Modélisation Et À La Commande De Réseaux Électriques À Structure Variable » Doctoral thesis, University Of Science And Technology Of Lille, Central School Of Lille

R. Zrafi, S. Ghedira, K. Besbes (2018) « A Bond Graph Approach for the Modeling and Simulation of a Buck Converter», Journal of Low Power Electronics and Applications 